\title{
GCU
}

Glasgow Caledonian

University

University for the Common Good

\section{An effective strategy to diagnose HIV infection: findings from a national audit of HIV partner notification outcomes in sexual health and infectious disease clinics in the UK}

Rayment, Michael; Carne, Chris; Bell, Gill; Estcourt, Claudia; Roberts, Jonathon ; Wilkinson, Natalie; Wilkins, Ed; Estreich, Steven; Morris, Georgina; Phattey, Jara; Sullivan, Ann

Published in:

BMJ

DOI:

10.1136/sextrans-2015-052532

Publication date:

2017

Document Version

Publisher's PDF, also known as Version of record

Link to publication in ResearchOnline

Citation for published version (Harvard):

Rayment, M, Carne, C, Bell, G, Estcourt, C, Roberts, J, Wilkinson, N, Wilkins, E, Estreich, S, Morris, G, Phattey, $\mathrm{J}$ \& Sullivan, A 2017, 'An effective strategy to diagnose HIV infection: findings from a national audit of HIV partner notification outcomes in sexual health and infectious disease clinics in the UK', BMJ, vol. 93, no. 2, pp. 94-99. https://doi.org/10.1136/sextrans-2015-052532

\section{General rights}

Copyright and moral rights for the publications made accessible in the public portal are retained by the authors and/or other copyright owners and it is a condition of accessing publications that users recognise and abide by the legal requirements associated with these rights.

Take down policy

If you believe that this document breaches copyright please view our takedown policy at https://edshare.gcu.ac.uk/id/eprint/5179 for details of how to contact us. 


\title{
An effective strategy to diagnose HIV infection: findings from a national audit of HIV partner notification outcomes in sexual health and infectious disease clinics in the UK
}

\author{
Michael Rayment, ${ }_{1}^{1}$ Hilary Curtis, ${ }^{2}$ Chris Carne, ${ }^{3}$ Hugo McClean, ${ }^{4}$ Gill Bell, ${ }^{5}$ \\ Claudia Estcourt, ${ }^{6}$ Jonathon Roberts, ${ }^{7}$ Ed Wilkins, ${ }^{8}$ Steven Estreich, ${ }^{9}$ \\ Georgina Morris, ${ }^{10}$ Jara Phattey, ${ }^{11}$ Ann K Sullivan, ${ }^{1}$ on behalf of the members of \\ the British Society for Sexual Health and HIV National Audit Group, and the British \\ HIV Association Audit and Standards Subcommittee
}

For numbered affiliations see end of article.

\section{Correspondence to Dr Michael Rayment, Consultant Physician, St Stephen's Centre, Chelsea and Westminster Hospital NHS Foundation Trust, 369 Fulham Road, London SW10 9NH, UK ; michaelrayment@nhs.net}

Received 31 December 2015 Revised 15 June 2016 Accepted 17 July 2016 Published Online First 5 August 2016

\section{ABSTRACT}

Objectives Partner notification (PN) is a key public health intervention in the control of STIs. Data regarding its clinical effectiveness in the context of HIV are lacking. We sought to audit HIV PN outcomes across the UK.

Methods All UK sexual health and HIV services were invited to participate. Clinical audit consisted of retrospective case-note review for up to 40 individuals diagnosed with HIV per site during 2011 (index cases) and a review of PN outcomes for up to five contacts elicited by PN per index case.

Results 169/221 (76\%) clinical services participated (93\% sexual health/HIV services, 7\% infectious diseases/ HIV units). Most (97\%) delivered PN for HIV. Data were received regarding 2964 index cases (67\% male; 50\% heterosexual, 52\% white). PN was attempted for $88 \%$ of index cases, and outcomes for 3211 contacts were audited (from an estimated total of 6400): 519 (16\%) were found not to be at risk of undiagnosed HIV infection, 1399 (44\%) were informed of their risk and had an HIV test, $310(10 \%)$ were informed of the risk but not known to have tested and 983 (30\%) were not informed of their risk of HIV infection. Of 1399 contacts tested through PN, 293 (21\%) were newly diagnosed with HIV infection. Regular partners were most likely to test positive $(p<0.001)$.

Conclusions HIV PN is a highly effective diagnostic strategy. Non-completion of PN thus represents a missed opportunity to diagnose HIV in at-risk populations. Vigorous efforts should be made to pursue PN to identify people living with, and at risk of, HIV infection.

\section{BACKGROUND}

Effective HIV testing strategies are urgently required in the UK: in $2014,17 \%$ of the estimated 103700 people living with HIV infection were unaware of their status, and $40 \%$ of new diagnoses were made late (defined as a CD4 count of $<350$ cells $/ \mu \mathrm{L}$ at diagnosis). ${ }^{1}$

By targeting exposed contacts, effective partner notification (PN) could reduce the undiagnosed fraction, diagnose people earlier in their infection and identify people at high risk of HIV for whom risk reduction interventions would be appropriate.
Given recent evidence regarding the impact of HIV diagnosis on risk behaviour and the effectiveness of antiretroviral therapy in preventing onward infection, ${ }^{2}{ }^{3}$ HIV PN would also be expected to have a public health impact in terms of averting incident infections.

Modelling studies support the value of $\mathrm{PN}$ in controlling HIV at a public health level ${ }^{4}$ and a meta-analysis of nine qualifying studies demonstrated a prevalence of newly diagnosed HIV in contacts of $20 \%$ overall $^{5}$ — an extremely high yield as a testing strategy. In practice, the vigorous PN strategies employed in Cuba are believed to have been instrumental in curtailing the nascent HIV epidemic. $^{6}$

In the UK, the National Institute for Health and Care Excellence recommends that all services providing care for people with STIs should either provide PN or refer to services that do. ${ }^{7}$ The British Association for Sexual Health and HIV (BASHH) has set minimum PN performance standards, for Chlamydia trachomatis and Neisseria gonorrhoeae. ${ }^{8}$ However, there is a lack of evidence to support the use of these standards in the management of other STIs, including HIV. Indeed, the epidemiology and natural history of HIV with frequent lack of clarity on time of acquisition, long clinical latent period and lower risk of transmission per sex act is likely to mean that standards and outcomes would be different from those for acute bacterial STIs.

Data regarding HIV PN outcomes in the UK are limited to audit reports from individual centres, the majority of which are unpublished. ${ }^{9}$ As a prelude to developing future PN outcomes and standards for use in the UK context, a national audit of HIV $\mathrm{PN}$ was undertaken jointly by BASHH and the British HIV Association (BHIVA) to provide baseline national level data of HIV PN performance and outcomes.

\section{METHODS}

All registered UK sexual health services and adult HIV clinical services $(n=221)$ were invited to participate. The audit opened in March 2013 and ran for 8 weeks. It was in two parts: 
1. The policy questionnaire that collected information regarding the provision of $\mathrm{PN}$ at each site (methods of $\mathrm{PN}$ employed; content of any local written policies on PN)

2. The clinical audit that consisted of a retrospective case-note review. Inclusion criteria: adults ( $>16$ years) newly diagnosed with HIV infection during the year 2011 (index cases), selected in reverse consecutive order from 31 December to 1 January, up to a maximum of 40 per site. This was a pragmatic maximum to ensure that large services were not overburdened and smaller clinics could be represented meaningfully. There were no exclusion criteria.

Clinical information was submitted electronically via webbased forms for index cases and for up to five contacts per index patient for feasibility reasons. For index cases, this included: current gender identity, ethnicity, age, HIV exposure risk, date of confirmatory HIV test, CD4 and HIV viral load at diagnosis, and likely duration of infection and how this was estimated (using clinical criteria such as symptoms of seroconversion, time since last negative HIV test, known date of possible exposure, serological test patterns (eg, evolving antibody response) and the use of the recent infection testing algorithm $\left(\right.$ RITA,$\left.{ }^{10}\right)$ where available). PN-related data included whether and by whom PN was performed and reason if not performed, date PN initiated, PN look back period and number of contacts elicited. Data relating to contacts included type of contact (sexual, injecting drug use, mother to child, other), type of partnership and nature of sex if sexual (regular, ex-regular, casual known, unknown, sexual behaviours and condom use), how much information for the contact was recorded (eg, first name, surname, telephone number), whether the contact was considered contactable, what PN action was agreed and PN outcome (including whether this was verified by a healthcare worker and dates this occurred and was recorded). Data relating to contacts derived from index case report and healthcare worker verification. For index cases reporting more than five contacts, participating centres defined the total number of contacts and then chose the five contacts for whom audit data were supplied.

Data were summarised in Microsoft Excel 2010 and statistical analysis was performed using $R$. (R: A Language and Environment for Statistical Computing; (2014) http://www. R-project.org)

Our main auditable outcomes comprised:

1. HIV PN initiation: the proportion of index cases (\%) for whom a discussion about PN was undertaken

2. HIV PN completion: the proportion of elicited contacts (\%) that were:

(i) informed of their exposure to HIV infection

(ii) attended a clinic for an HIV test as a result of PN (expressed as both patient report of attendance and healthcare worker verified report of attendance)

3. Prevalence (\%) of newly diagnosed HIV infection in tested contacts

HIV PN outcome 2(ii) was used to calculate $\mathrm{PN}$ ratios to enable comparison with BASHH National PN Standards. In the absence of HIV-specific PN standards, comparison was made with the performance standard for index/contact/healthcare worker-reported chlamydial PN (at least 0.6 contacts per index case; for healthcare worker-verified $\mathrm{PN}$ it is at least 0.4 contacts per index case $\left.{ }^{10}\right)$ :

1. Number of contacts per index case reported by the index, the contact or a healthcare worker as having attended a sexual health service for evaluation and testing as a result of PN
2. Number of contacts per index case verified by a healthcare worker as having attended a sexual health service for evaluation and testing as a result of PN

The ratios were calculated using aggregate data.

Finally, univariate analyses $\left(\chi^{2}\right.$ for categorical and t-test for non-categorical variables) were undertaken to identify associations between demographic variables in both index cases and contacts and the key outcomes of HIV PN completion and HIV prevalence in tested contacts.

\section{RESULTS}

Of the 221, $169(76 \%)$ services responded to the initial invitation to participate.

\section{Policy survey}

Survey responses were received from 156/221 (70\%) clinical services of which $73(47 \%)$ described themselves as sexual health services, $70(45 \%)$ as sexual health and HIV ( \pm infectious diseases) services and $13(7 \%)$ as infectious diseases/HIV units. All but four services (97\%) reported that they delivered PN for HIV. Nearly all sites providing PN offered patientinitiated and provider-referral $\mathrm{PN}(98 \%$ and 96\%, respectively). Contract PN was provided by $67 \%$. Twenty-three clinics (15\%) had access to the Gay Men Fight AIDS pilot online men who have sex with men (MSM) PN service (https://www. gmfa.org.uk/pn (accessed 15 April 2016)). Nineteen (12.2\%) services had a formal written policy or standard operating procedure referring to PN for HIV, and a further 91 (58\%) indicated that their policy was to follow national guidelines. Ten services $(6 \%)$ had a policy regarding how long PN should be continued. Of these, three services would stop within 3 months, three within 6 months and one within 1 year. Twelve $(8 \%)$ services had a policy on re-initiating PN in the event of a new sexual partner or STI diagnosis. Six (4\%) had a written policy regarding patients who refused to meaningfully engage in PN or refused to disclose, and a further 109 (70\%) had an agreed practice.

\section{Clinical audit}

Characteristics of the index cases

Audit responses were received from 169/221 (76\%) services. Audit reports described 2964 index cases. These were as follows: $1987(67.0 \%)$ male, $882(29.8 \%)$ female, $3(0.1 \%)$ transgender, $92(3.1 \%)$ sex not stated; 1483 (50.0\%) were exposed to HIV through heterosexual contact, $1252(42.2 \%)$ through sex between men, $15(0.5 \%)$ through injecting drug use, $214(7.2 \%)$ other or unstated. The ethnicity of index cases comprised 1533 (51.7\%) white, 984 (33.2\%) black African, $335(11.3 \%)$ other and $112(3.8 \%)$ unknown. Of index cases, $72(2.4 \%)$ were under 20 years, 679 (22.9\%) 20-29 years, 997 (33.6\%) 30-39 years, 736 (24.8\%) 40-49 years, $299(10.1 \%)$ 50-59 years, $113(3.8 \%) 60$ or over and 68 (2.3\%) had no age reported. Time from infection to diagnosis could be estimated for $53.6 \%(n=1590)$ of index cases; $23.7 \%(n=377)$ of these individuals were recently infected (within 6 months) with supporting RITA data being supplied for 57 index cases (15.1\%).

\section{Partner notification processes for index cases}

The PN process implemented per index case is summarised in figure 1. For $43(1.5 \%)$ index cases, it was explicitly stated that PN was completed in another centre: these individuals are henceforth excluded from the denominator, leaving a PN denominator of 2921 index cases. In contrast, 59 index cases described as 'patient transferred care' and 19 described as 


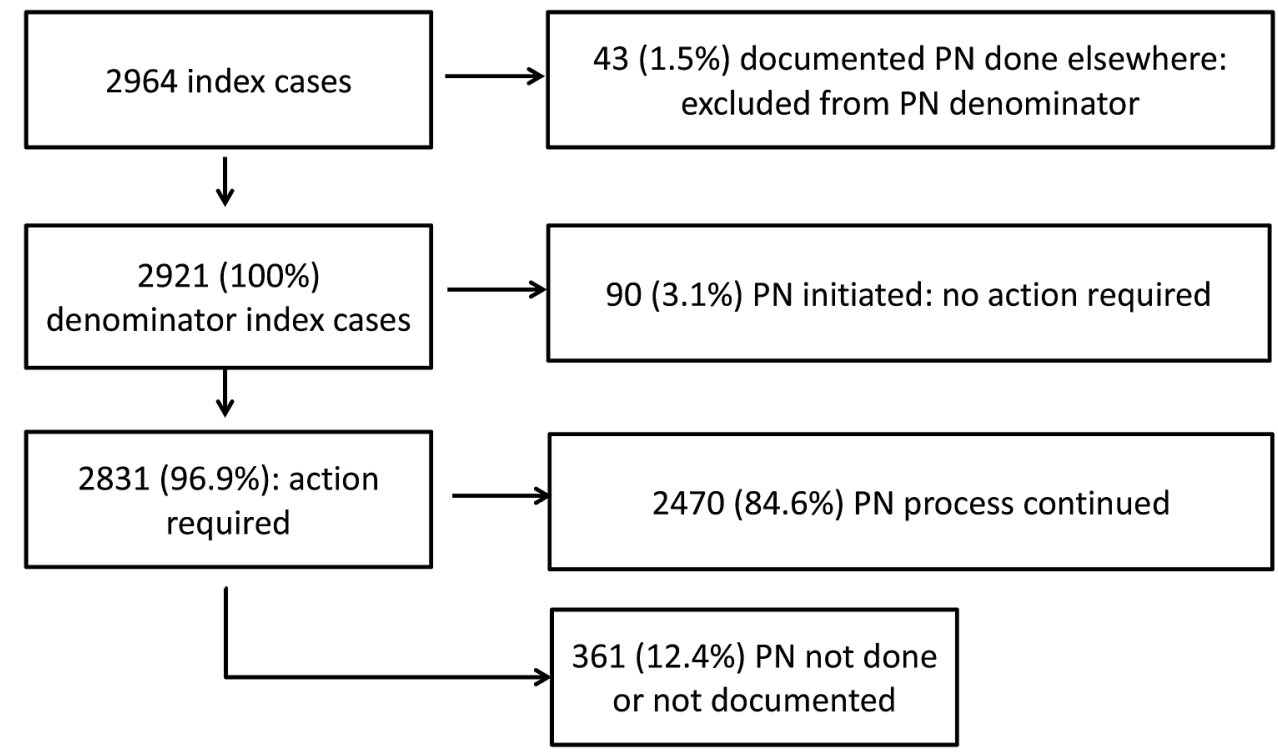

Figure 1 Partner notification processes per index case.

'patients routinely seen for HIV care elsewhere' were not excluded from the denominator, although it is possible that for some of these there may have been an agreement that PN would be done elsewhere.

Because of differing ways in which respondents reported index cases where the HIV risk status of elicited contacts was already known (eg, known already to be HIV positive, already tested, deceased, outside the UK/untraceable or deemed not at risk), we categorised index cases post hoc as shown in figure 1, as 'PN initiated: no action required' (90, 3.1\% of denominator index cases), 'PN process continued' $(2470,84.6 \%)$ or 'PN not done or not documented' $(361,12.4 \%)$. Hence, overall PN was performed to some degree for $87.6 \%$ of denominator index cases.

\section{Contacts elicited}

We received audit forms regarding 3211 contacts derived from the 2470 index cases for whom PN was continued. The index cases were, however, estimated to have over 6400 contacts in total. There were a small number of contacts $(n=54)$ for whom a form was not received because they were deemed not to be at risk of HIV infection (eg, their HIV status was already known, or they were deceased).

A total of 1051 index cases had only one contact, and 923 $(87.8 \%)$ of these contacts were audited. The median number of contacts per index case was 2, but the distribution of number of contacts varied by sex and sexuality, with MSM reporting a higher number of contacts. Because total number of contacts per index case was categorised when above $5(5-10,11-15,16-$ $20,21-25,26$ and above), we were unable to calculate a mean number of contacts by category.

\section{PN process and outcomes for audited contacts}

Outcomes for the 3211 audited contacts were as follows: 519 $(16.2 \%)$ were found not to be at risk of undiagnosed HIV infection (most commonly because their status was already definitively known, or they were deceased); 1399 (43.6\%) were informed of their risk and were either healthcare worker or patient verified as having attended a service for HIV testing as a result; 310 (9.7\%) were informed of the risk but were not known to have attended for testing; 983 (30.6\%) were not informed of their risk of HIV infection. Figure 2 summarises these outcomes in the form of a flow chart.

\section{HIV prevalence in tested contacts}

Of 1399 contacts tested as a result of HIV PN, 293 (20.9\%) were newly diagnosed with HIV infection (see table 1). Nine index cases were associated with two newly diagnosed contacts, and none with more than two. Based on the characteristics of the index case, heterosexual acquisition of HIV, Black African ethnicity and contact type were associated with positivity in tested contacts. Regular partners were more likely to test positive than ex-regular $(\mathrm{p}=0.002)$ and casual known contacts $(\mathrm{p}<0.001)$. A wide range in prevalence in tested contacts was observed across UK BASHH regions (from $9.5 \%$ in the Northern England region to $29.4 \%$ in Wales).

\section{Associations with non-completion of PN}

The only statistically significant difference in proportion of at-risk contacts who were notified was according to contact type with 1292/1422 (90\%) regular contacts, 339/577 (59\%) of ex-regular contacts, 373/562 (66\%) casual known contacts and $36 / 377(9.6 \%)$ of casual unknown notified, respectively $(\mathrm{p}<0.001)$.

\section{Time to completion of PN}

Time to completion of PN was known for 1057 at-risk audited contacts: $949(89.8 \%)$ attended for testing within 120 days after initiation of $\mathrm{PN}, 37$ (3.5\%) between 121 and 180 days, 45 (4.3\%) between 181 and 365 days and 26 (2.5\%) after more than 1 year.

Outcomes as defined by BASHH PN standards

HIV PN outcomes were calculated, with the following results:

0.45 contacts/index case were verified by healthcare worker as having attended a service for an HIV test

0.64 contacts/index case attended a service for an HIV test, including index case report

The total number of index cases (the denominator) for this calculation was 2921 (ie, all except those for whom it was documented that $\mathrm{PN}$ was done elsewhere). PN ratios showed minor variation when stratified by demographic variables of the index 


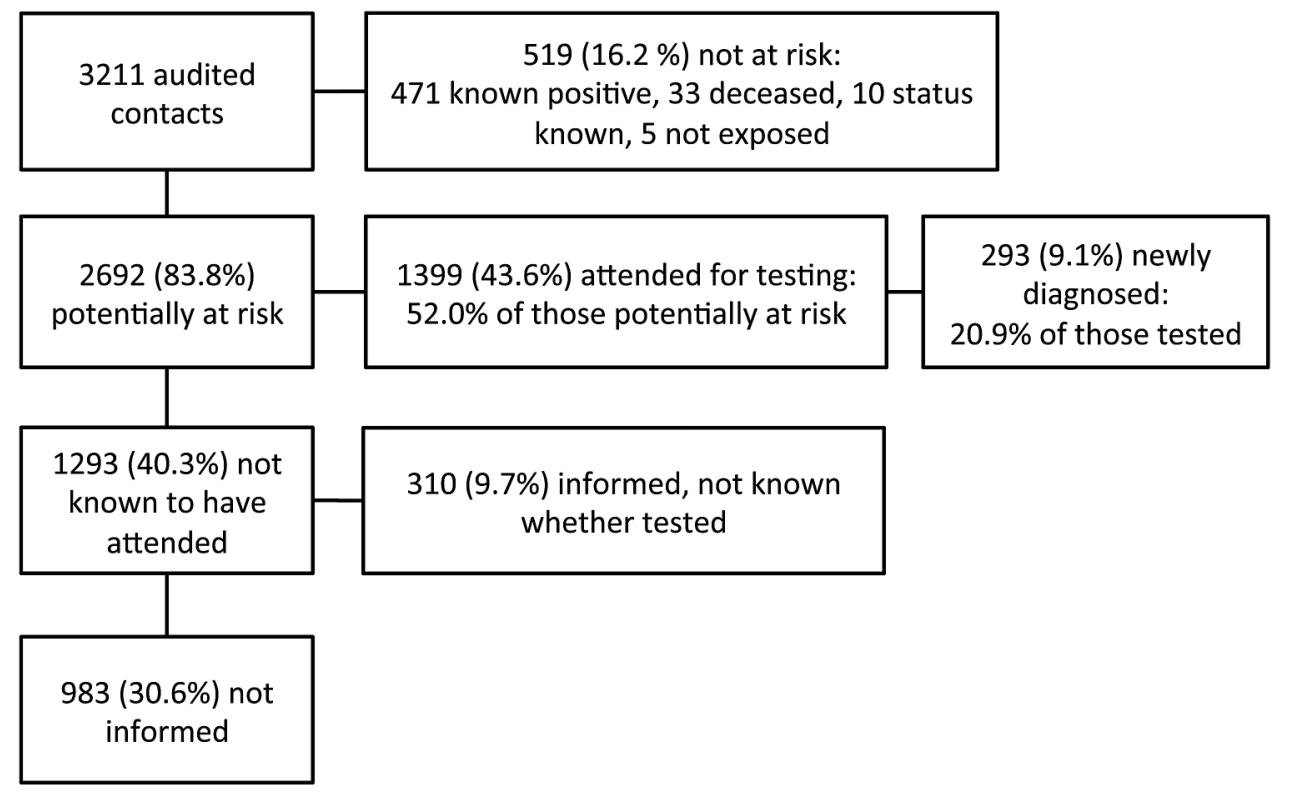

Figure 2 PN processes and outcomes for audited contacts $(n=3211)$.

Table 1 Prevalence of newly diagnosed HIV infection in tested contacts by index patient characteristics, and by sexual contact type

\begin{tabular}{|c|c|c|c|}
\hline & $\begin{array}{l}\text { Number of } \\
\text { contacts } \\
\text { tested }\end{array}$ & $\begin{array}{l}\text { Number testing HIV- } \\
\text { positive }(\%,(95 \% \mathrm{CI}))\end{array}$ & $\begin{array}{l}\text { p Value } \\
\text { (univariate } \\
\text { analysis) }\end{array}$ \\
\hline All tested contacts & 1399 & $293(20.9$ (18.77 to 23.03$))$ & \\
\hline \multicolumn{4}{|c|}{ Index patient characteristics } \\
\hline \multicolumn{4}{|l|}{ Sex } \\
\hline Male & 944 & $190(20.1$ (17.6 to 22.9$))$ & 0.21 \\
\hline Female & 425 & 99 (23.3 (19.4 to 27.7)) & \\
\hline \multicolumn{4}{|c|}{ Mode of HIV acquisition } \\
\hline Heterosexual & 694 & $163(23.5$ (20.4 to 26.9$))$ & 0.04 \\
\hline Homosexual & 609 & $113(18.6$ (15.6 to 21.9$))$ & \\
\hline \multicolumn{4}{|l|}{ Ethnicity } \\
\hline White & 784 & $153(19.5$ (16.8 to 22.5$))$ & 0.05 \\
\hline Black African & 419 & $103(24.6$ (20.6 to 29.0$))$ & \\
\hline \multicolumn{4}{|l|}{ Age } \\
\hline Under 40 & 893 & 185 (20.7 (18.1 to 23.6$))$ & 0.60 \\
\hline 40 or over & 480 & $106(22.1$ (18.5 to 26.1$))$ & \\
\hline \multicolumn{4}{|l|}{ Timing of infection } \\
\hline $\begin{array}{l}\text { Recent } \\
\text { (<6 months) }\end{array}$ & 188 & $35(18.6$ (13.5 to 25.1$))$ & 0.38 \\
\hline Not recent & 657 & $144(21.9(18.9$ to 25.3$))$ & \\
\hline \multicolumn{4}{|c|}{ Contact characteristics } \\
\hline \multicolumn{4}{|l|}{ Sexual contact type } \\
\hline Regular & 890 & 236 (26.5 (23.7 to 29.6)) & $<0.001$ \\
\hline Ex-regular & 176 & $24(13.6$ (9.1 to 19.8)) & \\
\hline Casual known & 197 & 23 (11.7 (7.9 to 17.2)) & \\
\hline
\end{tabular}

case (see table 2). Ratios were most improved if the index case reported a regular partner among audited contacts.

\section{DISCUSSION}

This is the first national audit of HIV PN outcomes and processes in the UK and it provides compelling data to support
Table 2 Variation in partner notification (PN) outcome measure by characteristics of index case

\begin{tabular}{ll}
\hline Characteristics of index patient & $\begin{array}{l}\text { PN ratio (contacts/index case } \\
\text { attending a service for an HIV } \\
\text { test, including patient report) }\end{array}$ \\
\hline All & 0.64 \\
Male & 0.66 \\
Female & 0.62 \\
Heterosexual & 0.63 \\
Homosexual & 0.69 \\
White & 0.72 \\
Black African & 0.56 \\
Under 40 & 0.69 \\
40 or over & 0.58 \\
Recently infected (within 6 months) & 0.76 \\
Not recently infected & 0.71 \\
Had audited regular partner & 1.03 \\
No audited regular partner & 0.42 \\
\hline
\end{tabular}

HIV PN as an effective diagnostic intervention. Of nearly 1400 patients tested as a result of HIV PN, 21\% were themselves newly diagnosed with HIV infection (293 new HIV diagnoses from 2921 audited index cases—a ratio of 1:10). However, PN was performed for only $88 \%$ of index cases, and was completed for fewer than half of their estimated total number of contacts. This illustrates both the striking effectiveness of HIV PN and the considerable scope for improvement in its delivery in the UK.

The policy questionnaire demonstrated comprehensive (>97\%) provision of HIV PN in sexual health and HIV services in the UK. The majority offered several PN approaches and followed national guidelines or a local written policy.

The 21\% prevalence of HIV among contacts tested as a result of $\mathrm{PN}$ in our audit is consistent with a meta-analysis of HIV PN. ${ }^{5}$ However, Sexual Health and HIV Activity Property Type (SHHAPT) surveillance reporting for 2014 indicates that 
only $5.6 \%$ of 1830 individuals who attended sexual health clinics in England as HIV PN contacts tested HIV positive. ${ }^{11}$ We believe that this discrepancy may reflect underuse of novel PN codes in the SHHAPT system. Biased sampling within our audit is also a possible factor (see Limitations below). HIV prevalence in tested contacts was higher in heterosexuals, regular and ex-regular partners, and black Africans. This likely reflects increased risk due to ongoing exposure in established relationships, confounding in terms of ethnicity and heterosexuality as a risk factor, and possible over-reporting of heterosexual contacts.

Initiation of PN nationally was $88 \%$, which falls short of the closest applicable BASHH audit standard of $97 \%$ of index cases having the outcome of (an) agreed contact action(s), or the decision not to contact, documented for all contacts. ${ }^{8}$ When expressed as a ratio of outcome/index case, the outcomes of 0.45 contacts/index case verified by healthcare worker as having attended a service, and 0.64 contacts/index case having attended a service including patient report meet the BASHH standards in use for C. trachomatis and N. gonorrhoeae PN outcomes. As a comparator, aggregate SHHAPT data in England in 2014 demonstrate that the number of tested contacts/index case was 0.54 for new diagnoses of HIV across all sexual health clinics. ${ }^{11}$ There was significant centre-to-centre and regional variation in these outcome measures; however, analysis of the data suggests that case mix variation was not wholly responsible for this variance (data not shown). This suggests that some differences in performance are due to operational differences at sites. However, some outliers were likely to be artefactual due to small numbers of index cases submitted in smaller centres.

Nationally, 30\% of elicited at-risk contacts were not informed of their risk of HIV infection. This compares with 37\% (range: $3 \%-67 \%$ ) in the meta-analysis previously described ${ }^{5}$ and does suggest that non-completion of PN is commonplace. In our audit, failure to conduct PN varied significantly by contact type. Applying the observed prevalence figures of newly diagnosed HIV infection in each of the contact types, we estimate that non-completion of PN among harder to reach contacts such as ex-regular and casual known partners means substantial numbers of individuals are failing to be diagnosed with HIV infection by this method. Indeed, assuming the same prevalence by contact type among tested and untested contacts, 422 potentially contactable sexual contacts were infected with HIV: 293 (69\%) were tested and diagnosed via PN and 129 (31\%) remained undiagnosed, with more than half of this undiagnosed group deriving from ex-regular and known-casual contacts, despite observed prevalence being lower in these groups. The driving issue is, we feel, failure to pursue PN by healthcare workers, rather than a reluctance to disclose partners at risk by the index cases.

\section{Limitations}

There are data quality issues in the audit, which, while unlikely to affect the national observations and conclusions, may have impacted on the outcomes at individual sites.

The first is the definition of 'PN' itself. Some centres used the term to mean the elicitation of contacts and the evaluation of their risk even if none were at risk of undiagnosed HIV infection. Other centres used the term PN only for contacts that required testing. We consider that the former is correct. We therefore created post-hoc definitions to deal with this discrepancy, although we were unable to fully correct for this.
We believe that our sample of index cases was broadly representative of all new HIV diagnoses in the UK in 2011. ${ }^{12}$ However, as we audited a maximum of five contacts per index case, we sampled only about half of all elicited contacts. Audited contacts were probably not representative of the entire population of contacts. Casual unknown contacts (or 'uncontactable') were undersampled, for example.

We did not collect data on type of PN used (eg, indexinitiated, provider referral) and this would have been of value to detect any differences in efficacy and effectiveness.

Finally, the use of the BASHH PN standards to measure effectiveness and performance of HIV PN is problematic, as ratios developed for C. trachomatis and N.gonorrhoeae are unlikely to be directly transferable to HIV with its different epidemiology, natural history and transmission risk per exposure.

We would therefore propose developing new measures of HIV PN to measure both performance and effectiveness more sensitively, taking into account these specific features.

These concerns aside, this audit demonstrates that HIV PN is a highly effective strategy to diagnose HIV infection, and is a powerful tool when vigorously pursued. However, we found considerable scope for improvement in PN performance, suggesting that at-risk individuals are being denied the opportunity to test. A recent European Centre for Disease Control report suggests huge variability in the legal and clinical contexts for provision of $\mathrm{PN}$ in the management of STIs including HIV across the European region. ${ }^{13}$ Many countries lack support and consistency in the delivery of PN. In the UK, we are in a privileged position with national clinical guidelines, and a legal and commissioning framework to mandate and support PN. Thus, poor performance should be challenged. All centres should examine their outcomes closely, and work as a clinical team and with their local stakeholders and commissioners to maximise HIV PN outcomes. Changes to the commissioning of sexual health and HIV services in some of the devolved nations of the UK, resulting in the possible fragmentation of the two, must not be to the detriment of health interventions such as HIV PN, which straddle the divide.

\section{Key messages}

- HIV partner notification (PN) is an effective strategy to diagnose undiagnosed HIV: $21 \%$ of audited contacts tested as a result of PN were newly diagnosed with HIV infection.

- PN was initiated for $88 \%$ of index cases, but fewer than half of all contacts elicited were known to have attended for an HIV test.

- PN was more likely to be completed for regular and ex-regular partners, who themselves were more likely to test positive for HIV infection.

- Failure to undertake effective PN denies at-risk populations the opportunity to test for HIV and benefit from earlier access to treatment and risk reduction interventions for those found to be HIV negative.

\footnotetext{
Author affiliations

${ }^{1}$ Directorate of HIV/GU Medicine, Chelsea and Westminster NHS Foundation Trust, London, UK

${ }^{2}$ Audit and Standards Sub-committee, British HIV Association, London, UK ${ }^{3}$ Genitourinary Medicine, Cambridge Community Services, Cambridge, UK

${ }^{4}$ City Health Care Partnership, Hull, Kingston Upon Hull, UK

${ }^{5}$ Department of GU Medicine, Royal Hallamshire Hospital, Sheffield, UK
} 
${ }^{6}$ Reader in Sexual Health and HIV, Barts and the London School of Medicine and Dentistry, Centre for Immunology and Infectious Disease, London, UK

${ }^{7}$ Brighton and Sussex University Hospital NHS Trust, Brighton, East Sussex, UK

${ }^{8}$ Department of Infectious Diseases, North Manchester General Hospital,

Manchester, UK

${ }^{9}$ Epsom and St Helier University Hospitals NHS Trust, Surrey, UK

${ }^{10}$ Department of Genitourinary Medicine, Leeds Teaching Hospitals NHS Trust, Leeds, UK

${ }^{11}$ Genitourinary Medicine, Whittall Street Clinic, University Hospitals Birmingham NHS Foundation Trust, Birmingham, UK

\section{Handling editor Jackie A Cassell}

Twitter Follow Michael Rayment at @mikeyrayment

Collaborators Members of BASHH National Audit Group: Ann Sullivan, Hugo McClean, Chris Carne, Vanessa Apea, Anatole Menon-Johansson, Meena Gupta, Liz Anderson, Huw Price, Andy Williams, Sarup Tayal, Say Quah, Cara Saxon, Gill Wildman, Ciara Cunningham, Amelia Hughes, Andrew DeBurgh-Thomas, Steven Ostrich, Manjula Pammi, Meena Sethupathi, Sara Scofield, Sumit Bhaduri, Maneh Farazmand, Emma Street, Sophie Brady, Michael Rayment, David Daniels, Helen Wiggins, Erna Buitendam, John Saunders, Helen Ward, Jamie Hardie. Members of the BHIVA Audit and Standards Sub-committee: Andrew Freedman, Ann Sullivan, Brian Angus, David Asboe, Garry Brough, Fiona Burns, David Chadwick, Duncan Churchill, Valerie Delpech, Katja Doerholt, Yvonne Gillette, Aoife Molloy, Chinyere Okoli, Ed Ong, Alison Rodger, Caroline Sabin, Julie Musonda, Sonia Raffe, Michael Rayment.

Contributors All authors designed the audit, coordinated data collection and reviewed and analysed the data. MR drafted the article and all authors reviewed it. Members of the BASHH National Audit Group and BHIVA Audit and Standards Subcommittee contributed to the design, conduct and analysis of the audit.

Funding This audit was funded by the National Audit Group of the British Association of Sexual Health and HIV, and by the Audit and Standards Subcommittee of the British HIV Association.

Competing interests None declared.

Provenance and peer review Not commissioned; externally peer reviewed.

Data sharing statement All original and unpublished data are available on request. Please direct enquiries to Hilary Curtis at: hilary@regordane.net.

\section{REFERENCES}

1 HIV in the UK: Situation Report 2015. Incidence, prevalence and prevention. Public Health England [November 2015] https://www.gov.uk/government/uploads/system/ uploads/attachment_data/file/477702/HIV_in_the_UK_2015_report.pdf

2 Fox J, White PJ, Macdonald N, et al. Reductions in HIV transmission risk behaviour following diagnosis of primary HIV infection: a cohort of high-risk men who have sex with men. HIV Med 2009;10:432-8.

3 Cohen MS, Chen YQ, McCauley M, et al. Prevention of HIV-1 infection with early antiretroviral therapy. N Engl J Med 2011;365:493-505.

4 Hsieh YH, Wang YS, de Arazoza $\mathrm{H}$, et al. Modeling secondary level of HIV contact tracing: its impact on HIV intervention in Cuba. BMC Infect Dis 2010;10:194.

5 Hogben M, McNally T, McPheeters M, et al. The effectiveness of HIV partner counseling and referral services in increasing identification of HIV-positive individuals a systematic review. Am J Prev Med 2007;33(2 Suppl):S89-100.

6 de Arazoza H, Joanes J, Lounes $R$, et al. The HIV/AIDS epidemic in Cuba: description and tentative explanation of its low HIV prevalence. BMC Infect Dis 2007;7:130.

7 National Institute for Health and Clinical Excellence. Public Health Intervention Guidance PH03. Preventing sexually transmitted infections and under 18 conceptions. http://guidance.nice.org.uk/PH3 (accessed 15 Oct 2015).

8 British Association of Sexual Health and HIV. BASHH Statement on Partner Notification for Sexually Transmissible Infections. 2012 http://www.bashh.org/ documents/4445.pdf (accessed 15 Oct 2015).

9 National AIDS Trust. HIV Partner Notification: a missed opportunity? 2012. http:// www.nat.org.uk/media/Files/Publications/May-2012-HIV-Partner-Notification.pdf (accessed 15 Oct 2015).

10 Aghaizu A, Murphy G, Tosswill J, et al. Recent infection testing algorithm (RITA) applied to new HIV diagnoses in England, Wales and Northern Ireland, 2009 to 2011. Euro Surveill 2014;19:pii: 20673.

11 Public Health England. Sexually transmitted infections (STIs): annual data tables [Table 6: STI diagnoses \& partner notification, 2012-14. [June 2015] https://www. gov.uk/government/uploads/system/uploads/attachment_data/file/436732/2014_ Table_6_STI_diagnoses__partner_notification.xls (accessed 15 Oct 2015).

12 HIV in the United Kingdom: 2012 Report. Health Protection Agency [November 2012] https://www.gov.uk/government/uploads/system/uploads/attachment_data/file/ 335452/HIV_annual_report_2012.pdf (accessed 15 Apr 2016).

13 Public Health Benefits of Partner Notification for Sexually Transmitted Infections including HIV: Technical Report. European Centre for Disease Control [June 2013] http://ecdc.europa.eu/en/publications/Publications/Partner-notification-for-HIV-STIJune-2013.pdf (accessed 15 Apr 2016). 


\section{STI An effective strategy to diagnose HIV infection: findings from a national audit of HIV partner notification outcomes in sexual health and infectious disease clinics in the UK}

Michael Rayment, Hilary Curtis, Chris Carne, Hugo McClean, Gill Bell, Claudia Estcourt, Jonathon Roberts, Ed Wilkins, Steven Estreich, Georgina Morris, Jara Phattey and Ann K Sullivan

Sex Transm Infect 2017 93: 94-99 originally published online August 5, 2016

doi: 10.1136/sextrans-2015-052532

Updated information and services can be found at:

http://sti.bmj.com/content/93/2/94

\section{These include:}

References This article cites 6 articles, 0 of which you can access for free at: http://sti.bmj.com/content/93/2/94\#BIBL

Email alerting service

Receive free email alerts when new articles cite this article. Sign up in the box at the top right corner of the online article.

\section{Notes}

To request permissions go to:

http://group.bmj.com/group/rights-licensing/permissions

To order reprints go to:

http://journals.bmj.com/cgi/reprintform

To subscribe to BMJ go to:

http://group.bmj.com/subscribe/ 